\title{
Investigating prenatal perceived support as protective factor against adverse birth outcomes: A community cohort study
}

Mathilde Duroux ${ }^{\mathrm{a}}$, Suzannah Stuijfzand ${ }^{\mathrm{b}}$, Vania Sandoz ${ }^{\mathrm{b}}$ and Antje Horsch $^{\mathrm{b}, \mathrm{c} *}$

${ }^{a}$ Department of Psychology, University of Fribourg, Fribourg, Switzerland; ${ }^{b}$ Institute of Higher Education and Research in Healthcare (IUFRS), University of Lausanne, Lausanne, Switzerland; 'Department Women-Mother-Child, Lausanne University Hospital, Lausanne, Switzerland

Prof. Antje Horsch, Institute of Higher Education and Research in Healthcare (IUFRS), University of Lausanne, SV-A, Route de la Corniche 10, 1010 Lausanne, Switzerland. Phone: + 412131485 71. Antje.Horsch@chuv.ch 


\section{Investigating prenatal perceived support as protective factor against adverse birth outcomes: A community cohort study}

Background: Studies show that prenatal maternal anxiety may act as a risk factor for adverse neonatal and obstetric outcomes, whilst prenatal social support may rather act as a protective factor. However, studies examining and linking prenatal anxiety symptoms, prenatal perceived support, and neonatal and/or obstetric outcomes are lacking.

Objective: The aims of this cross-sectional cohort study were to investigate whether, in a community sample, prenatal perceived support: (1) had a protective influence on birth outcomes (gestational age (GA), birthweight (BW), 5-minute Apgar score, and mode of delivery); (2) acted as a protective factor, moderating the relationship between anxiety symptoms and the aforementioned birth outcomes.

Method: During their third trimester of pregnancy, 182 nulliparous child-bearers completed the anxiety scale of the Hospital Anxiety and Depression Scale (HADSA) measuring anxiety symptoms, and the Medical Outcome Study Social Support Survey (MOS-SSS) measuring perceived support. Birth outcomes data was extracted from medical records.

Results: (1) Regression models inclusive of perceived support did not significantly predict any birth outcomes. However, the model inclusive of perceived tangible support - a MOS-SSS subscale assessing perceived material/financial aid and assistance with daily tasks - significantly positively predicted the 5-minute Apgar score. (2) Hierarchical multiple regression models indicated that perceived support did not significantly moderate the relationship between anxiety symptoms and birth outcomes. However, perceived tangible support significantly moderated the relationship between anxiety symptoms and the 5-minute Apgar score.

Conclusion: These findings suggest that when experienced within non-clinical thresholds, prenatal anxiety symptoms do not increase the risk of adverse neonatal and obstetric outcomes when perceived support is present.

Keywords: birth outcomes, prenatal anxiety, social support, maternal mental health, pregnancy 


\section{Introduction}

Although pregnancy is often perceived as a happy time, it is not uncommon for childbearers to experience mental health problems, such as anxiety, when faced with the concerns and worries that this specific period raises (Madhavanprabhakaran et al., 2015). Based on a meta-analysis reviewing 102 studies, maternal prenatal anxiety is indeed common, with $24.6 \%$ of child-bearers being affected in the third trimester (Dennis et al., 2017). Prenatal anxiety refers to unique and distinct concerns, such as the ability to be a good mother, to be financially secure, or to have a safe delivery (Deklava et al., 2015). Prenatal anxiety may affect foetal development through psychosocial and biological mechanisms (Littleton et al., 2007), and may thus predict adverse neonatal outcomes (Alder et al., 2007; Ding et al., 2014; Grigoriadis et al., 2018). In addition, prenatal anxiety has been associated with fear of childbirth, which is a risk factor for adverse obstetric outcomes (Madhavanprabhakaran et al., 2013).

Adverse neonatal outcomes include preterm birth (PTB), low birthweight (LBW), and a poor 5-minutes Apgar score. The World Health Organization [WHO] $(2014 ; 2018)$ defines PTB when childbirth occurs before 37 weeks of gestation, and LBW when birthweight (BW) is inferior or equal to 2500 grams, regardless of gestational age (GA). A poor 5-minute Apgar score reflects poor outcomes on the Apgar standardised assessment, a measure evaluating the physical condition of newborns 5 minutes after birth (Casey et al., 2001). These adverse neonatal outcomes are associated with infant mortality and morbidity - they affect up to 9\% of births per year in Europe (Blencowe et al., 2019; Ernest et al., 2019; Goldenberg et al., 2008). This is not to mention their negative impact on the mental health of mothers in the postpartum (Greene et al., 2015; Holditch-Davis et al., 2015). Adverse obstetric outcomes include the mode of delivery. Some modes of delivery, typically unplanned operative deliveries (e.g., emergency caesarean sections), 
can trigger significant psychological distress, such as guilt, anger or even postpartum posttraumatic stress disorder in the mother (Grekin \& O'Hara, 2014; Horsch et al., 2017).

Adverse neonatal and obstetric outcomes are major public health issues, as they concern a substantial proportion of pregnancies and have detrimental consequences, including medical, psychological, and economic consequences (Bauer et al., 2014; Petrou, 2003; Segre et al., 2014). It therefore seems important to focus on protective factors that may play a role in reducing their occurrence - social support is one such factor (Orr et al., 2004).

Social support is defined as the perception (perceived support) or experience (received support) that one is loved and cared for by others, esteemed and valued, and part of a social network of mutual assistance and obligations (Wills, 1991). Studies have shown that social support has a positive impact on the health and wellbeing of childbearers (Orr et al., 2004), especially if it is perceived. Indeed, believing that one will get support in times of need seems to be more effective than actually getting the support (Uchino, 2009). Of note, studies do not always differentiate between perceived and received support and often use the generic term of social support.

The literature identifies different categories of support, whether perceived or received: tangible support (i.e., material and financial aid and assistance with daily tasks), emotional support (i.e., expression of love and affection), and informational support (i.e., advice and guidance) (Cohen \& Syme, 1985). These types of support serve specific goals and functions, and are of different importance depending on the context (Cohen \& Syme, 1985). The literature review by Gjerdingen et al. (1991) showed that prenatal tangible and emotional support were related to child-bearers' mental wellbeing - which in turn protects from potential adverse neonatal outcomes; and that prenatal informational support was related to decreased complications during labour and delivery. 
Two hypotheses regarding the protective effect of (perceived and received) social support have been proposed: the main effect and the stress-buffering effect (Cohen \& Syme, 1985). The main effect argues that social support directly improves the overall sense of wellbeing and offers general health protection independently from the current level of stress one is experiencing. The stress-buffering effect, on the other hand, argues that social support indirectly improves the overall sense of wellbeing by counteracting the effects of stress and anxiety through provision of resources and help. In the perinatal context, the main effect of social support was reported in several studies (Costa et al., 2000; Elsenbruch et al., 2006; Feldman et al., 2000; Zachariah, 2009), as was the stressbuffering effect (Ghosh et al., 2010; Glazier et al., 2004; Norbeck \& Tilden, 1983). The overall findings therefore support the idea that prenatal social support has a positive impact on the health and wellbeing of mothers and babies (Dunkel-Schetter, 2011; Orr et al., 2004). However, generalisation of results is difficult, as the concepts, measures, and outcomes vary widely in the literature and are not always properly defined (DunkelSchetter, 2011).

So far, few observational studies have specifically investigated prospective associations between prenatal perceived support, prenatal anxiety symptoms and neonatal and/or obstetric outcomes; even fewer have differentiated the different forms that social support can take. Furthermore, little research was carried out in samples with non-clinical anxiety levels. The current research aimed to address these issues.

\section{Aims and objectives}

The main objectives of this prospective cohort study were to explore whether, in a community sample, perceived support: (1) had a protective influence on GA, BW, the 5minute Apgar score, and the mode of delivery, testing the main-effect of perceived 
support; (2) acted as a protective factor, moderating the relationship between anxiety symptoms and the aforementioned birth outcomes, testing the stress-buffering effect of perceived support. As little research was carried out within non-clinical samples, this study also allowed us to explore how the role of perceived support differed depending on the nature of the population. Based on previous evidence, we predicted that perceived support would have a protective influence on birth outcomes and would moderate the relationship between anxiety symptoms and birth outcomes (Orr et al., 2004). We also predicted that the different kinds of perceived support (i.e., perceived tangible, emotional and informational support) would not necessarily have the same predictive effect on all birth outcomes (Gjerdingen et al., 1991).

\section{Materials and methods}

\section{Study design and participants}

This prospective cohort study used a subsample of the Lausanne Perinatal Wellbeing Cohort (LPWC), which was approved by the ethics committee for research in humans of the Canton de Vaud, Switzerland (approval number: 480/2012). The LPWC is an ongoing cohort study being conducted at a Swiss university hospital. It assesses the wellbeing and mental health of future parents from the third trimester of pregnancy to six months postpartum through self-report questionnaires. The current study focused on maternal data collected during the third trimester of pregnancy.

Inclusion criteria for the LPWC study participation were: being $\geq 18$ years old, understanding French, and not suffering from a current psychotic illness or severe intellectual disability. The following inclusion criteria were added for the present study: being nulliparous and having completed the prenatal anxiety and social support assessments during the third trimester. The final sample comprised 182 child-bearers. We 
took a conservative approach and expected the presence of a medium effect size $\left(\mathrm{f}^{2}=\right.$ 0.15) regarding the impact of prenatal mental health on birth outcomes (Cohen, 1988). With an alpha of .05 and power of .95 , the required sample size for the first and second research questions were respectively $n=89$ and $n=119$.

\section{Measurements}

\section{Prenatal anxiety}

Prenatal anxiety symptoms were measured with the anxiety scale of the Hospital Anxiety and Depression Scale (HADS-A) (Zigmond \& Snaith, 1983). The HADS-A includes 7 items, each of them rated on a three-points scale (0-3) in reference to the last seven days. Items are not pregnancy-focused and assess general anxiety, as shown by the following example: «Worrying thoughts go through my mind». By adding the scores of all items, a final total score ranging from 0 to 21 is obtained. The literature review of Bjelland et al. (2002) identified a cut-off score at 8: scoring less than 8 indicates no anxiety, scoring 8 to 10 indicates possible anxiety, and scoring 11 to 21 indicates probable anxiety. The validated French version has good psychometric properties (Untas et al., 2009). The HADS-A showed adequate internal consistency in our sample $(\alpha=.68)$.

\section{Prenatal perceived support}

Prenatal perceived support was measured with the Medical Outcome Study Social Support Survey (MOS-SSS) (Sherbourne \& Stewart, 1991). The MOS-SSS is a 20-item self-assessment questionnaire including four subtypes of perceived support: a) perceived tangible support $(\alpha=94)$, i.e., material and financial aid and assistance with daily tasks, (b) perceived emotional / informational support $(\alpha=.83)$, i.e., emotional support and advice, (c) perceived affectionate support $(\alpha=88)$, i.e., expression of love and affection, 
(d) perceived positive social interaction $(\alpha=90)$, i.e., the availability of the entourage to do activities. Items are short and easily understandable, as reflected by the following four examples, respectively: (a) "Someone to help you if you were confined to bed", (b) "Someone you can count on to listen to you when you need to talk", (c) "Someone who shows you love and affection", (d) "Someone to have a good time with". Items have to be rated on a Likert scale from 1 (= none of the time) to 5 (= all of the time); the final results provide a total score, as well as four sub-scores. A higher score indicates greater perceived support. Given the lack of a French validated version, the MOS-SSS was translated and culturally adapted according to the forward-backward method (Wild et al., 2005). The MOS-SSS showed excellent internal consistency in our sample $(\alpha=.96)$.

\section{Neonatal and obstetric outcomes}

Both neonatal and obstetric outcomes were retrieved from medical records. Neonatal outcomes included BW in grams, GA in days, and the 5-minute Apgar score. The 5minute Apgar score assessed different aspects of the newborn health - heart rate, respiratory effort, muscle tone, reflex irritability and colour - each ranging from 0 to 2 . If the sum score equals or exceeds 7 out of 10, the baby's vital prognosis is deemed to be good (Casey et al., 2001). The 5-minute Apgar score (versus 1-, 3- or 10-minute) was used in this study because it best predicts infant health outcomes (Casey et al., 2001).

Obstetric outcomes included the mode of delivery, which was divided into three categories: vaginal delivery, planned operative delivery (i.e., elective and iterative caesarean section), and unplanned operative delivery (i.e., vacuum delivery, forceps, and emergency caesarean section). 


\section{Statistical analyses}

To address our first research question, multiple linear regressions and multinomial logistic regressions were performed. To address our second research question, moderation analyses were carried out using three-steps hierarchical regressions and multinomial logistic regressions.

Participants whose questionnaires were left blank were removed from the analyses; the remaining $1.2 \%$ of missing data was imputed based on different predictors. All analyses were controlled for the following sociodemographic and obstetric variables: age, educational background, ethnicity, migrant status, gestity, history of perinatal loss, and history of traumatic delivery before 24 weeks of GA. The significance was reached at $p<0.05$.

\section{Results}

\section{Characteristics of the sample}

In total, 182 child-bearers aged 18 to 42 years old $(M=31.79, S D=4.26)$ participated in the study. Table 1 displays the demographic and obstetric characteristics of the sample.

\section{[Table 1]}

GA ranged from 35 to 42 weeks, with $2.2 \%$ of newborns considered preterm $(<$ 37 weeks). BW ranged from 1180 to 4580 grams, with $3.3 \%$ of newborns considered LBW ( $\leq 2500$ grams). The 5-minute Apgar scores ranged from 2 to 10 , with $0.5 \%$ of newborns having a poor score at 5 minutes $(<7)$. Regarding the mode of childbirth, $48.4 \%$ of child-bearers had spontaneous deliveries, $15.9 \%$ had planned operative deliveries, and $35.7 \%$ had unplanned operative deliveries. 
The HADS-A total score ranged from 0 to 16, with $9.3 \%$ of child-bearers reaching the probable clinical anxiety threshold. The MOS-SSS total score ranged from 2.14 to 5 , with a mean score of $4.39(S D=.63)$.

\section{The protective influence of perceived support on birth outcomes}

The regression models inclusive of control variables and perceived support did not significantly predict any birth outcomes: $\mathrm{GA}\left(F(8,137)=.84, p=.57, R^{2}=.046\right)$; $\mathrm{BW}$ $\left(F(8,137)=1.34, p=.23, R^{2}=.072\right)$; the 5-minute Apgar score $(F(8,137)=1.60, p=$ $\left..13, R^{2}=.085\right)$; or the mode of delivery $\left(X^{2}(14)=18.24, p=.20, R^{2}=.117\right)$.

The regression model inclusive of control variables and perceived tangible support $(\beta=.21, t=2.57, p=.01)$ significantly predicted the 5-minute Apgar score $(F(8$, $\left.137)=2.12, p=.04, R^{2}=.110\right)$. The three other regression models inclusive of control variables and the remaining perceived support subscales were non-significant for all birth outcomes (Table 2).

\section{[Table 2]}

The moderator effect of perceived support on prenatal anxiety symptoms - birth outcomes relationship

The regression models testing the moderator effect of perceived support on the association between prenatal anxiety symptoms and birth outcomes, and inclusive of control variables, found that perceived support and prenatal anxiety symptoms did not significantly contribute to the prediction of any birth outcomes: $\mathrm{GA}(F(10,135)=.89, p$ $\left.=.55, R^{2}=.062\right) ; \mathrm{BW}\left(F(10,135)=1.28, p=.25, R^{2}=.087\right)$; the 5-minute Apgar score $\left(F(10,135)=1.83, p=.06, R^{2}=.119\right) ;$ and the mode of delivery $\left(X^{2}(12)=24.04, p=.15\right.$, $\left.R^{2}=.152\right)$. 
The regression model testing the moderator effect of perceived tangible support on the association between prenatal anxiety symptoms and the 5-minute Apgar score, and inclusive of control variables, found that perceived tangible support and prenatal anxiety symptoms $(\beta=1.37, t=2.13, p=.04)$ significantly contributed to the prediction of the 5minute Apgar score $\left(F(10,135)=2.52, p=.01, R^{2}=.157\right)($ Figure 1$)$.

\section{[Figure 1]}

All the other regression models testing the moderator effect of the remaining perceived support subscales were non-significant for all birth outcomes. For the sake of brevity, only the last step of the moderation analyses was reported in Table 3.

\section{[Table 3]}

\section{Discussion}

This prospective community cohort study aimed to investigate whether perceived support had positive effects on birth outcomes, and whether it interacted with anxiety symptoms to predict birth outcomes. Results revealed that perceived support did not have a protective influence on GA, BW, the 5-minute Apgar score or the mode of delivery. Perceived support also did not moderate the relationship between anxiety symptoms and these birth outcomes. However, when testing the different subscales of perceived support separately, results revealed that perceived tangible support was predictive of the 5-minute Apgar score: the higher the perceived tangible support, the better the 5-minute Apgar score. Perceived tangible support was also found to moderate the relationship between anxiety symptoms and the 5-minute Apgar score, indicating an interaction effect. In a context of high levels of perceived tangible support, the 5-minute Apgar score improved as the level of anxiety symptoms increased; however, in a context of low levels of 
perceived tangible support, the 5-minute Apgar score decreased as the level of anxiety symptoms increased.

Contrary to previous studies showing that perceived support might be beneficial for the health of the child-bearer and her baby (Dunkel-Schetter, 2011), we found no protective influence of perceived support on any of the birth outcomes. The present study thus did not provide evidence of a main, nor of a stress-buffering effect of perceived support.

Various factors may account for these results, starting with the characteristics of our population. Indeed, it seems that our community sample is over-representative of healthy participants. Only $9.3 \%$ of child-bearers reached the probable clinical anxiety threshold score, reflecting low rates of mental distress compared to the $24.6 \%$ reported in the meta-analysis of Dennis et al. (2017). Correspondingly, only 4.4\% of newborns faced adverse neonatal outcomes, which is lower than the $9.4 \%$ reported in the general Swiss population (OFS, 2019). Of note, however, is that conducting our research on a community sample, rather than on a clinical sample, may allow for broader generalisation of results and, consequently, more inclusive care. In addition, it shows that perceived support behaves in ways that differ between high-risk and community samples.

Our sample also displayed mainly favourable and protective characteristics, such as being in a couple relationship or being university educated. To complete the picture, it would have been interesting to have access to the child-bearers' SES - this would also have allowed us to compare current resources with perceived resources, and how it may vary depending on the SES; however we do not hold this data. Our sample also reported a very high average level of perceived support. This raises the question whether those who agreed to participate were more likely to have a good mental health and social support than those who declined. It is indeed conceivable that child-bearers with mental 
distress may refuse to participate because they consider involvement in the study as an additional (mental) burden, and that lack of support during recruitment is a barrier to participation in such a study. It is also possible that the self-reported recording of prenatal anxiety and perceived support were subject to a social desirability bias (Zerbe \& Paulhus, 1987). Child-bearers may indeed feel ashamed or guilty about feeling anxious or not being sufficiently supported, which may cause them to exaggerate their responses in a positive way.

The type of anxiety examined in this study, namely general anxiety, may also explain our findings. There is indeed a type of specific anxiety that may be more suited to our area of research: the pregnancy-related anxiety, which is defined as maternal worries related to pregnancy, childbirth and parenting (Huizink et al., 2004). General anxiety and pregnancy-related anxiety can be considered as two different concepts, considering their association with adverse birth outcomes: while results are mixed for the former, they are consistent across studies for the latter (Brunton et al., 2015). We can therefore speculate that if we had focused on pregnancy-related anxiety, our results might have differed.

Perceived tangible support was found to contribute to the prediction of the 5minute Apgar score, whether assessed directly or as a moderator. Although every kind of perceived support has its own importance, perceived tangible support might prevent child-bearers from poor neonatal and obstetric outcomes associated with physical activities and constraints (Bonzini et al., 2007). However, the question arises as to why the 5-minute Apgar score is the only birth outcome being predicted by perceived tangible support. This suggests that the 5-minute Apgar score is more sensitive to perceived tangible support than to other types of perceived support, indicating that the association 
between the different types of perceived support and birth outcomes is linked to different mechanisms. Future research should be conducted to better understand this influence.

\section{Clinical implications}

Our results may convey an encouraging message for child-bearers - it appears that when experienced within non-clinical thresholds, prenatal anxiety symptoms do not increase the risk of adverse neonatal and obstetric outcomes in the presence of prenatal perceived support. These results underline the importance of screening for perceived support, a practice which is not yet systematic during prenatal visits and which could shed significant light on the child-bearers' surroundings. Furthermore, by reframing anxiety as a normative experience that does not impact the health of the baby, these results may reassure child-bearers during their pregnancy and usefully inform society as a whole.

Our results also highlight the importance of perceived tangible support, although this was only partially confirmed. Knowing that perceived tangible support is an important predictor of child-bearers' health, and consequently of that of their newborns, can provide interesting avenues for actions. Antenatal specialists may raise awareness regarding its relevance and, if it is lacking, may develop with the child-bearers ways to augment it among their current social environment.

\section{Conclusion}

Contrary to previous research, this study investigated the role of perceived support within a community sample with mostly non-clinical anxiety levels. Thus, our results showed for the first time that maternal prenatal anxiety symptoms, when experienced within nonclinical thresholds, do not increase the risk of adverse neonatal and obstetric outcomes in the presence of maternal prenatal perceived support. 


\section{Acknowledgments}

We would like to thank Prof. Dominik Schöbi (University of Fribourg, Switzerland) for his advice and all the child-bearers who agreed to participate in this study. Furthermore, we are grateful to the Lausanne Perinatal Research Group, especially Cassie Pernet, Joanne Horisberger, Lara Schütz, Yasmina Lotfi Mahmoud, Lauranne Jan du Chêne, Priska Udriot, Anna Favero, Leah Gilbert, and Céline Favrod for their precious help with recruitment and data collection. Finally, we thank Professors Tolsa, Vial, and Baud for institutional support.

\section{Disclosure of interest}

The authors report no conflict of interest.

\section{Funding}

No funding was provided for this work but $\mathrm{AH}$ is a management committee member of COST action CA18211. 


\section{References}

Alder, J., Fink, N., Bitzer, J., Hösli, I., \& Holzgreve, W. (2007). Depression and anxiety during pregnancy: A risk factor for obstetric, fetal and neonatal outcome? A critical review of the literature. The Journal of Maternal-Fetal \& Neonatal Medicine, 20(3), 189-209. https://doi.org/10.1080/14767050701209560

Bauer, A., Parsonage, M., Knapp, M., Lemmi, V., Adelaja, B. (2014). The costs of perinatal mental health problems. Centre for Mental Health and London School of Economics, London.

Bjelland, I., Dahl, A. A., Haug, T. T., \& Neckelmann, D. (2002). The validity of the Hospital Anxiety and Depression Scale: An updated literature review. Journal of Psychosomatic Research, 52(2), 69-77. https://doi.org/10.1016/S0022$\underline{\text { 3999(01)00296-3 }}$

Blencowe, H., Krasevec, J., de Onis, M., Black, R. E., An, X., Stevens, G. A., Borghi, E., Hayashi, C., Estevez, D., \& Cegolon, L. (2019). National, regional, and worldwide estimates of low birthweight in 2015, with trends from 2000: A systematic analysis. The Lancet Global Health, 7(7), 849-860. https://doi.org/10.1016/S2214-109X(18)30565-5

Bonzini, M., Coggon, D., \& Palmer, K. T. (2007). Risk of prematurity, low birthweight and preeclampsia in relation to working hours and physical activities: A systematic review. Occupational and Environmental Medicine, 64(4), 228-243. http://dx.doi.org/10.1136/oem.2006.026872

Brunton, R. J., Dryer, R., Saliba, A., \& Kohlhoff, J. (2015). Pregnancy anxiety: A systematic review of current scales. Journal of Affective Disorders, 176, 24-34. https://doi.org/10.1016/j.jad.2015.01.039

Casey, B. M., McIntire, D. D., \& Leveno, K. J. (2001). The continuing value of the Apgar score for the assessment of newborn infants. New England Journal of Medicine, 344(7), 467-471. https://doi.org/10.1056/NEJM200102153440701

Cohen, J. (1988). Statistical Power Analysis for the Behavioral Sciences, 2nd Edition. Routledge

Cohen, S., \& Syme, S. L. (1985). Social support and health. Academic Press.

Costa, D. D., Dritsa, M., Larouche, J., \& Brender, W. (2000). Psychosocial predictors of labor/delivery complications and infant birth weight: A prospective multivariate study. Journal of Psychosomatic Obstetrics \& Gynecology, 21(3), 137-148. https://doi.org/10.3109/01674820009075621

Deklava, L., Lubina, K., Circenis, K., Sudraba, V., \& Millere, I. (2015). Causes of anxiety during pregnancy. Procedia-Social and Behavioral Sciences, 205, 623-626. https://doi.org/10.1016/j.sbspro.2015.09.097

Dennis, C. L., Falah-Hassani, K., \& Shiri, R. (2017). Prevalence of antenatal and postnatal anxiety: systematic review and meta-analysis. The British Journal of 
Psychiatry, 210(5), 315-323. https://doi.org/10.1192/bjp.bp.116.187179

Ding, X. X., Wu, Y. L., Xu, S. J., Zhu, R. P., Jia, X. M., Zhang, S. F., Huang, K., Zhu, P., Hao, J. H., \& Tao, F. B. (2014). Maternal anxiety during pregnancy and adverse birth outcomes: A systematic review and meta-analysis of prospective cohort studies. Journal of Affective Disorders, 159, 103-110. https://doi.org/10.1016/j.jad.2014.02.027

Dunkel-Schetter, C. (2011). Psychological science on pregnancy: Stress processes, biopsychosocial models, and emerging research issues. Annual Review of Psychology, 62, 531-558. https://doi.org/10.1146/annurev.psych.031809.130727

Elsenbruch, S., Benson, S., Rücke, M., Rose, M., Dudenhausen, J., Pincus-Knackstedt, M. K., Klapp, B. F., \& Arck, P. C. (2006). Social support during pregnancy: Effects on maternal depressive symptoms, smoking and pregnancy outcome. Human Reproduction, 22(3), 869-877. https://doi.org/10.1093/humrep/del432

Ernest, E., Wainstock, T., Sheiner, E., Segal, I., Landau, D., \& Walfisch, A. (2019). Apgar score and long-term respiratory morbidity of the offspring: A population-based cohort study with up to 18 years of follow-up. European Journal of Pediatrics, 178(3), 403-411. https://doi.org/10.1007/s00431-018-03311-6

Feldman, P. J., Dunkel-Schetter, C., Sandman, C. A., \& Wadhwa, P. D. (2000). Maternal Social Support Predicts Birth Weight and Fetal Growth in Human Pregnancy. Psychosomatic Medicine, 62(5), 715. https://doi.org/10.1097/00006842200009000-00016

Ghosh, J. K. C., Wilhelm, M. H., Dunkel-Schetter, C., Lombardi, C. A., \& Ritz, B. R. (2010). Paternal support and preterm birth, and the moderation of effects of chronic stress: A study in Los Angeles County mothers. Archives of Women's Mental Health, 13(4), 327-338. https://doi.org/10.1007/s00737-009-0135-9

Gjerdingen, D. K., Froberg, D. G., \& Fontaine, P. (1991). The effects of social support on women's health during pregnancy, labor and delivery, and the postpartum period. Family medicine, 23(5), 370-375.

Glazier, R. H., Elgar, F. J., Goel, V., \& Holzapfel, S. (2004). Stress, social support, and emotional distress in a community sample of pregnant women. Journal of Psychosomatic Obstetrics \& Gynecology, 25(3-4), 247-255. https://doi.org/10.1080/01674820400024406

Goldenberg, R. L., Culhane, J. F., Iams, J. D., \& Romero, R. (2008). Epidemiology and causes of preterm birth. The Lancet, 371(9606), 75-84. https://doi.org/10.1016/S0140-6736(08)60074-4

Greene, M. M., Rossman, B., Patra, K., Kratovil, A. L., Janes, J. E., \& Meier, P. P. (2015). Depressive, anxious and perinatal post-traumatic distress in mothers of very low birth weight infants in the NICU. Journal of Developmental and Behavioral Pediatrics: JDBP, 36(5), 362. https://doi.org/10.1097/DBP.0000000000000174

Grekin, R., \& O’Hara, M. W. (2014). Prevalence and risk factors of postpartum 
posttraumatic stress disorder: A meta-analysis. Clinical Psychology Review, 34(5), 389-401. https://doi.org/10.1016/j.cpr.2014.05.003

Grigoriadis, S., Graves, L., Peer, M., Mamisashvili, L., Tomlinson, G., Vigod, S. N., Dennis, C. L., Steiner, M., Brown, C., \& Cheung, A. (2018). Maternal Anxiety During Pregnancy and the Association With Adverse Perinatal Outcomes: Systematic Review and Meta-Analysis. The Journal of Clinical Psychiatry, 79(5). https://doi.org/10.4088/jcp.17r12011

Holditch-Davis, D., Santos, H., Levy, J., White-Traut, R., O’Shea, T. M., Geraldo, V., \& David, R. (2015). Patterns of psychological distress in mothers of preterm infants. Infant Behavior and Development, 41, 154-163. https://doi.org/10.1016/j.infbeh.2015.10.004

Horsch, A., Vial, Y., Favrod, C., Harari, M. M., Blackwell, S. E., Watson, P., Iyadurai, L., Bonsall, M.B. \& Holmes, E. A. (2017). Reducing intrusive traumatic memories after emergency caesarean section: A proof-of-principle randomized controlled study. Behaviour Research and Therapy, 94, 36-47. http://doi.org/10.1016/j.brat.2017.03.018

Huizink, A. C., Mulder, E. J., de Medina, P. G. R., Visser, G. H., \& Buitelaar, J. K. (2004). Is pregnancy anxiety a distinctive syndrome? Early Human Development, 79(2), 81-91. https://doi.org/10.1016/j.earlhumdev.2004.04.014

Littleton, H. L., Breitkopf, C. R., \& Berenson, A. B. (2007). Correlates of anxiety symptoms during pregnancy and association with perinatal outcomes: A metaanalysis. American Journal of Obstetrics and Gynecology, 196(5), 424-432. https://doi.org/10.1016/j.ajog.2007.03.042

Madhavanprabhakaran, G. K., Kumar, K. A., Ramasubramaniam, S., \& Akintola, A. A. (2013). Effects of pregnancy related anxiety on labour outcomes: A prospective cohort study. Journal of Research in Nursing and Midwifery, 2(7), 96-103.

Madhavanprabhakaran, G. K., D’Souza, M. S., \& Nairy, K. S. (2015). Prevalence of pregnancy anxiety and associated factors. International Journal of Africa Nursing Sciences, 3, 1-7. https://doi.org/10.1016/j.ijans.2015.06.002

Norbeck, J. S., \& Tilden, V. P. (1983). Life stress, social support, and emotional disequilibrium in complications of pregnancy: A prospective, multivariate study. Journal of Health and Social Behavior, 30-46. https://doi.org/10.2307/2136301

Office fédéral de la statistique (2020). Santé des nouveau-nés. https://www.bfs.admin.ch/bfs/fr/home/statistiques/sante/etat-sante/santenouveau-nes.html

Orr, S. T. (2004). Social Support and Pregnancy Outcome: A Review of the Literature. Clinical Obstetrics and Gynecology, 47(4), 842. https://doi.org/10.1097/01.grf.0000141451.68933.9f

Petrou, S. (2003). Economic consequences of preterm birth and low birthweight. An International Journal of Obstetrics \& Gynaecology, 110, 17-23. 
https://doi.org/10.1046/j.1471-0528.2003.00013.x

Segre, L. S., McCabe, J. E., Chuffo-Siewert, R., \& O’Hara, M. W. (2014). Depression and anxiety symptoms in mothers of newborns hospitalized on the neonatal intensive care unit. Nursing Research, 63(5), 320. https://doi.org/10.1097/NNR.0000000000000039

Sherbourne, C. D., \& Stewart, A. L. (1991). The MOS social support survey. Social Science \& Medicine, 32(6), 705-714. https://doi.org/10.1016/02779536(91)90150-B

Uchino, B. N. (2009). Understanding the links between social support and physical health: A life-span perspective with emphasis on the separability of perceived and received support. Perspectives on Psychological Science, 4(3), 236-255. https://doi.org/10.1111/j.1745-6924.2009.01122.x

Untas, A., Aguirrezabal, M., Chauveau, P., Leguen, E., Combe, C., \& Rascle, N. (2009). Anxiété et dépression en hémodialyse: Validation de l'Hospital Anxiety and Depression Scale (HADS). Néphrologie \& Thérapeutique, 5(3), 193-200. https://doi.org/10.1016/j.nephro.2009.01.007

Wild, D., Grove, A., Martin, M., Eremenco, S., McElroy, S., Verjee-Lorenz, A., \& Erikson, P. (2005). Principles of good practice for the translation and cultural adaptation process for patient-reported outcomes (PRO) measures: Report of the ISPOR Task Force for Translation and Cultural Adaptation. Value in Health, 8(2), 94-104. https://doi.org/10.1111/j.1524-4733.2005.04054.x

Wills, T. A. (1991). Social support and interpersonal relationships. Review of Personality and Social Psychology, 12, 265-289

World Health Organisation (2014). Global Nutrition Targets: 2025: Low birth weight policy brief.

https://www.who.int/nutrition/publications/globaltargets2025_policybrief_lbw/e $\underline{\mathrm{n} /}$

World Health Organisation (2018, February 19). Preterm birth. https://www.who.int/news-room/fact-sheets/detail/preterm-birth

Zachariah, R. (2009). Social support, life stress, and anxiety as predictors of pregnancy complications in low-income women. Research in Nursing \& Health, 32(4), 391404. https://doi.org/10.1002/nur.20335

Zerbe, W. J., \& Paulhus, D. L. (1987). Socially desirable responding in organizational behavior: A reconception. Academy of Management Review, 12(2), 250-264. https://doi.org/10.5465/amr.1987.4307820

Zigmond, A. S., \& Snaith, R. P. (1983). The Hospital Anxiety and Depression Scale. Acta Psychiatrica Scandinavica, 67(6), 361-370. https://doi.org/10.1111/j.16000447.1983.tb09716.x 


\section{Figure 1}

Moderation of the effect of anxiety on the 5-minute Apgar score at values of the moderator perceived tangible support

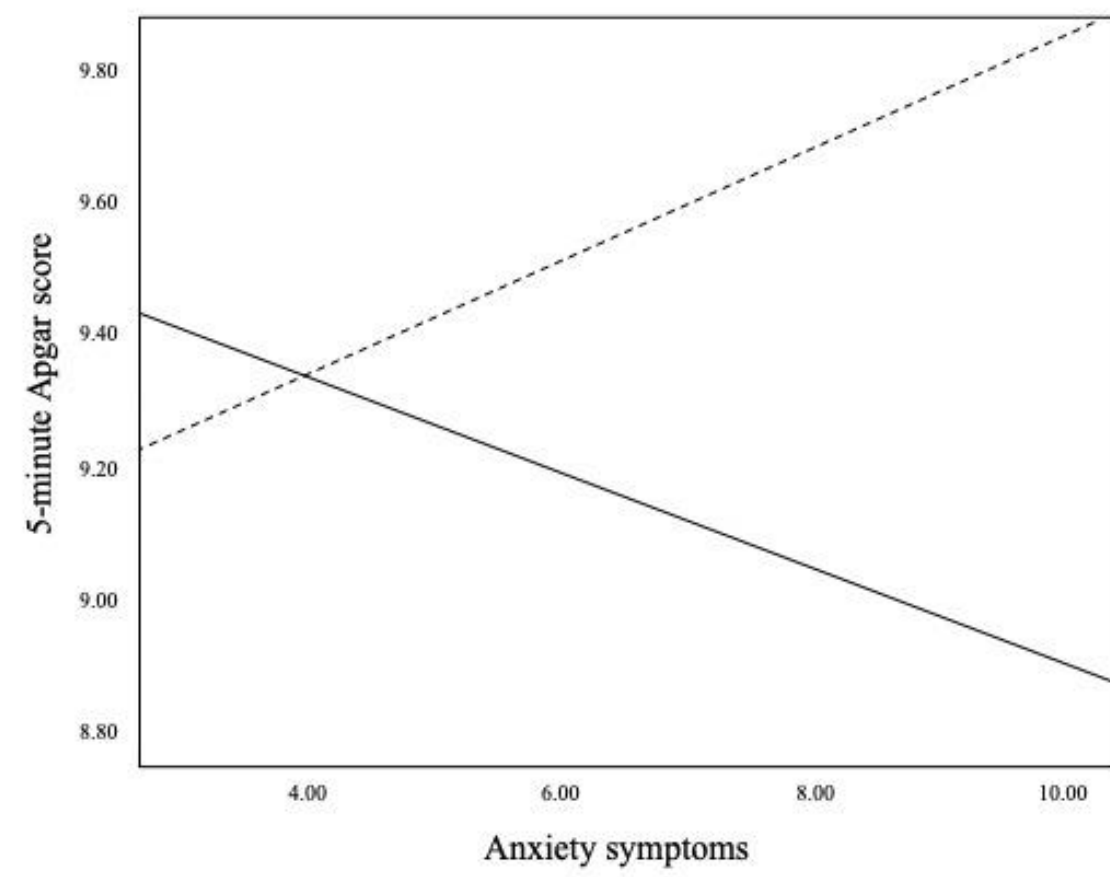

---- High perceived tangible support

— Low perceived tangible support 


\section{Table 1}

Demographic and obstetric characteristics of the sample

\begin{tabular}{|c|c|c|}
\hline & \multicolumn{2}{|c|}{$\begin{array}{l}\text { Mothers } \\
(n=182)\end{array}$} \\
\hline Age, year $(M, S D)$ & 31.79 & 4.26 \\
\hline \multicolumn{3}{|l|}{ Nationality } \\
\hline Swiss ( $n, \%)$ & 100 & 54.9 \\
\hline European $(n, \%)$ & 71 & 39 \\
\hline Non-European ( $n, \%)$ & 11 & 6 \\
\hline \multicolumn{3}{|l|}{ Ethnicity } \\
\hline Europe $(n, \%)$ & 147 & 80.8 \\
\hline Latin America $(n, \%)$ & 0 & 0 \\
\hline Africa $(n, \%)$ & 8 & 4.4 \\
\hline Caribbean $(n, \%)$ & 1 & 0.5 \\
\hline North America ( $n, \%)$ & 3 & 1.6 \\
\hline Asia $(n, \%)$ & 1 & 0.5 \\
\hline Other $(n, \%)$ & 1 & 0.5 \\
\hline Missing data $(n, \%)$ & 21 & 11.5 \\
\hline \multicolumn{3}{|l|}{ Migrant status } \\
\hline Swiss ( $n, \%)$ & 100 & 54.9 \\
\hline Non-Swiss $(n, \%)$ & 82 & 45.1 \\
\hline \multicolumn{3}{|l|}{ Educational background } \\
\hline Middle school $(n, \%)$ & 5 & 2.7 \\
\hline Secondary school $(n, \%)$ & 13 & 7.1 \\
\hline Apprenticeship (n, \%) & 35 & 19.2 \\
\hline University graduate or equivalent $(n, \%)$ & 117 & 64.3 \\
\hline Other & 12 & 6.6 \\
\hline \multicolumn{3}{|l|}{ Marital status } \\
\hline Married, common-law relationship ( $n, \%)$ & 120 & 65.9 \\
\hline Single $(n, \%)$ & 60 & 33 \\
\hline Divorced $(n, \%)$ & 1 & 0.5 \\
\hline Other $(n, \%)$ & 1 & 0.5 \\
\hline \multicolumn{3}{|l|}{ Pregnancy type } \\
\hline Single $(n, \%)$ & 172 & 94,5 \\
\hline Twins $(n, \%)$ & 10 & 5,5 \\
\hline \multicolumn{3}{|l|}{ Gestity } \\
\hline $1(n, \%)$ & 142 & 78 \\
\hline $2(n, \%)$ & 32 & 17,6 \\
\hline $3(n, \%)$ & 6 & 3,3 \\
\hline $4(n, \%)$ & 2 & 1,1 \\
\hline \multicolumn{3}{|l|}{ History of traumatic delivery before 24 weeks of GA } \\
\hline Yes $(n, \%)$ & 3 & 1.6 \\
\hline No $(n, \%)$ & 164 & 90.1 \\
\hline Missing data & 15 & 8.2 \\
\hline \multicolumn{3}{|l|}{ History of perinatal loss } \\
\hline Yes $(n, \%)$ & 30 & 16.5 \\
\hline No $(n, \%)$ & 137 & 75.3 \\
\hline Missing data $(n, \%)$ & 15 & 8.2 \\
\hline
\end{tabular}

Note. If a participant had another nationality in addition to the Swiss nationality, she was classified in the Swiss category - it is considered that this participant would have a Swiss social base and support.

\section{Table 2}


Regression model results for the subscales of the MOS-SSS for each birth outcome

\begin{tabular}{|c|c|c|c|c|c|c|c|c|c|c|c|c|}
\hline & \multicolumn{3}{|c|}{ GA } & \multicolumn{3}{|c|}{ BW } & \multicolumn{3}{|c|}{$\begin{array}{c}\text { 5-min Apgar } \\
\text { score }\end{array}$} & \multicolumn{3}{|c|}{ Mode of delivery } \\
\hline & $R^{2}$ & $F$ & $p$ & $R^{2}$ & $F$ & $p$ & $R^{2}$ & $F$ & $p$ & $R^{2}$ & $x^{2}$ & $p$ \\
\hline PTS & $\begin{array}{c}.04 \\
9\end{array}$ & .88 & .54 & .068 & $\begin{array}{c}1.2 \\
5\end{array}$ & .27 & .110 & $\begin{array}{c}2.1 \\
2\end{array}$ & $\begin{array}{c}.04 \\
*\end{array}$ & $\begin{array}{c}.10 \\
3\end{array}$ & 15.94 & .32 \\
\hline PEIS & $\begin{array}{c}.05 \\
5\end{array}$ & $\begin{array}{c}1.0 \\
0\end{array}$ & .44 & .077 & $\begin{array}{c}1.4 \\
3\end{array}$ & .19 & .087 & $\begin{array}{c}1.6 \\
2\end{array}$ & .12 & $\begin{array}{c}.11 \\
6\end{array}$ & 17.94 & .21 \\
\hline PAS & $\begin{array}{c}.05 \\
0\end{array}$ & .90 & .52 & .061 & $\begin{array}{c}1.1 \\
2\end{array}$ & .35 & .067 & $\begin{array}{c}1.2 \\
4\end{array}$ & .28 & $\begin{array}{c}.11 \\
1\end{array}$ & 17.17 & .25 \\
\hline PPSI & $\begin{array}{c}.05 \\
0\end{array}$ & .91 & .51 & .079 & $\begin{array}{c}1.4 \\
6\end{array}$ & .18 & .075 & $\begin{array}{c}1.3 \\
8\end{array}$ & .21 & $\begin{array}{c}.10 \\
3\end{array}$ & 15.87 & .32 \\
\hline
\end{tabular}

Note 1. $\mathrm{PES}=$ perceived tangible support, PEIS = perceived emotional and informational support, PAS = perceived affectionate support, PPSI $=$ perceived positive social interaction. Note $2 .{ }^{*} \mathrm{p}<.05$ 


\section{Table 3}

Third step of the moderation analysis tested for each subscales of social support for each birth outcomes

\begin{tabular}{|c|c|c|c|c|c|c|c|c|c|c|c|c|}
\hline \multicolumn{13}{|c|}{ Model 3} \\
\hline & \multicolumn{3}{|c|}{ GA } & \multicolumn{3}{|c|}{ BW } & \multicolumn{3}{|c|}{ 5-min Apgar score } & \multicolumn{3}{|c|}{ Mode of delivery } \\
\hline & $R^{2}$ & $F$ & $p$ & $R^{2}$ & $F$ & $p$ & $R^{2}$ & $F$ & $p$ & $R^{2}$ & $x^{2}$ & $p$ \\
\hline PTS & .062 & .89 & .54 & .080 & 1.17 & .32 & .157 & 2.52 & $.01^{*}$ & .126 & 19.67 & .35 \\
\hline PEIS & .071 & 1.03 & .42 & .086 & 1.28 & .25 & .113 & 1.72 & .08 & .147 & 23.24 & .18 \\
\hline PAS & .061 & .87 & .56 & .062 & .90 & .54 & .098 & 1.46 & .16 & .134 & 20.92 & .28 \\
\hline PPSI & .062 & .90 & .54 & .082 & 1.21 & .29 & .099 & 1.48 & .15 & .128 & 19.95 & .34 \\
\hline
\end{tabular}

Note 1. PTS = perceived tangible support; PEIS = perceived emotional and informational support; PAS = perceived affectionate support; PPSI $=$ perceived positive social interaction. Note $2 . * p<.05$ 